\title{
Extraction of Oil in Cleaning Oily Waste in Helio Devices Equipped with Concentrating Elements
}

\author{
Abdibattayeva M. ${ }^{1, a}$, Umbetbekov A. ${ }^{2, b}$, Kalimbetov $G^{3, c}$, Beketova $A^{4, d}$ \\ ${ }^{1}$ Al-Farabi Kazakh National University, Almaty Technological University, Republic of Kazakhstan, \\ ${ }^{2}$ Al-Farabi Kazakh National University, Almaty Technological University, Republic of Kazakhstan, \\ ${ }^{3}$ Evrasian technological University, Republic of Kazakhstan, \\ ${ }^{4}$ Evrasian technological University, Almaty Technological University, Republic of Kazakhstan, \\ amaralabdibattaeva@gmail.com, bashat.talgat@mail.ru, cgala_84_11@mail.ru, dbeketova.aigul@m \\ ail.ru
}

Keywords: solar energy; solar energy concentrator; solar module; Helio device; oily waste; heat treatment; heat carrying agent.

\begin{abstract}
Possible solutions of this problem and environmental security are considered in this article, solutions are based on a scientific study on recovery and recycling of oily waste. The method of oil extraction in the purification of oil-containing wastes using solar energy is worked out, given method based on alternative methods of influencing the hydrocarbon structure. The experimental setup to extract oil in the purification of oil-contaminated waste is developed and described in detail. The results of experimental studies are given on the purification of waste oil in Helio device equipped with concentrating elements. Physical and chemical researches of the petropolluted waste before and after thermal treatment with application of solar energy are also conducted.
\end{abstract}

\section{Introduction}

Oil refining and petrochemical industry plays an important role in the economy of any country, but they have a significant negative impact on the environment. Oily waste is formed at all stages of oil production and refining that is caused both imperfection of equipment and technology, and a human factor. To reduce the effects of oily waste a lot of methods are currently developed of treatment and disposal [1].

Relevance of processing of oily waste is confirmed with economically expedient and ecologically effective technologies, which allow to return the lost high-valuable hydrocarbons in economic circulation and competently to process them in oil products of a high value added.

The main objective is to find efficient technology and environmentally acceptable methods of cleaning sludge from mechanical impurities, water and salt and prepare the selected hydrocarbon concentrate for subsequent qualified processing. Attractive solution is the involvement of alternative energy sources in the processing of waste oil [2].

The main tendencies of modern power development is wide use of nonconventional and renewable sources, as well as the development and implementation of energy-saving technologies in traditional power [3].

Solar energy has the largest potential among all the alternative and renewable energy sources. The potential of solar energy as one of the main types of renewable energy sources (RES) has today predisposition to large-scale development around the world, including in Kazakhstan.

The territory of the Republic of Kazakhstan is sufficiently provided with energy of the Sun that defines prospectivity of solar power. The average annual sunshine duration in Kazakhstan is 20003000 hours.

The distribution of solar radiation on areas of Kazakhstan is given in Fig. 1; it is calculated on the total mean annual amount of direct solar radiation on a horizontal surface [4].

For example, in the north, in Kostanay, the number of hours of sunshine is equal to 2132 hours, and in the south, in Kyzylorda, this indicator is equal to 3062 hours. It is established that number of 
clear days in a year in the north - 120 , in the south - 260. Total radiation in northern Kazakhstan is $100 \mathrm{kcal} / \mathrm{cm}^{2}$ per year, in the southen $-155 \mathrm{kcal} / \mathrm{cm}^{2}$.

Thus, use of solar energy in oil and gas sector has great potential in system of the treatment of oil products.

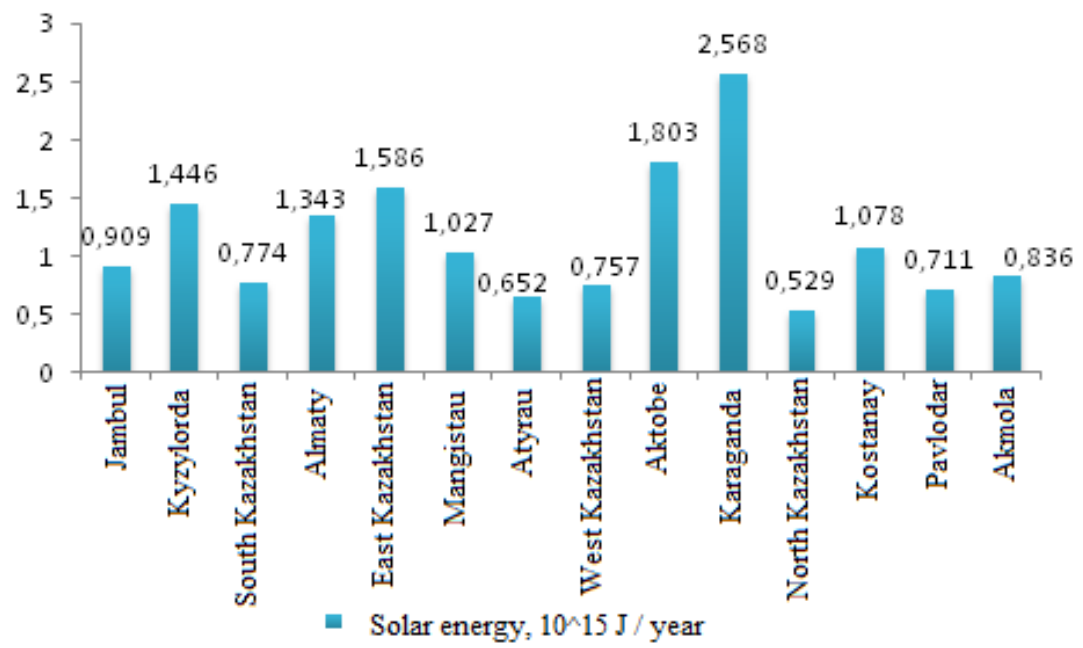

Fig.1. Distribution of solar energy potential on areas of the Republic of Kazakhstan

\section{Materials and methods}

Wide variation in composition and properties of raw materials and potential oil sludge and its tendency to form stable emulsions, or to phase separation, require careful study and determine the need for a universal technology using innovative technical solutions. We offered the universal, industrially realized way of purification of oily waste. The device is manufacturedwherehydrocarbons of oil products are exposed to deep heat treatment [5].

This unit has the following characteristics: power $250 \mathrm{~W} \pm 3 \%$; focal temperature reaches $120{ }^{\circ} \mathrm{C}$. Oily waste cleaningis carried out in a cylinder-shaped, the radiator of a solar collector is fixed inside, diameter $15 \mathrm{~mm}$ and more. The built-in parabolic concentrator collects all solar energy falling on it in a focus point, where the copper pipe is locatedoriented to the Sun. Missing heat in a cloudy and cold season is provided by the solar panel $300 \mathrm{~W} \pm 3 \%$.

The device operates as follows:petropolluted soil or sludge is mixed with water to create the conditions of oil displacement of soil, and the channels are formed after soil saturation with water, through which in the course of heating at the expense of solar energy, fractions of oil start being allocated. One more advantage of this heliodevice is its being automatized i.e. solar collector automaticallymoves on solar trajectories, as much as possible focusing solar radiation[6]. A schematic diagram of Helio device equipped with concentrating elements is in Fig. 2.

The developed way of cleaning of oil waste provides the maximum release of hydrocarbons, without prejudice to their chemical structure.

\section{Results and discussion}

Experimental studies were carried out in Almaty. Solar radiation of this area is $1,343 \cdot 10^{15} \mathrm{~J}$ per year. The table of total insolation on months of Almaty is given below [7].

Table 1 Total monthly insolation Almaty.

\begin{tabular}{|c|c|c|c|c|c|c|c|c|c|c|c|c|}
\hline \multirow[t]{2}{*}{ region } & \multicolumn{12}{|c|}{ Total monthly, $\mathrm{J} / \mathrm{m}^{2}\left(\mathrm{~kW} \cdot \mathrm{h} / \mathrm{m}^{2}\right)$} \\
\hline & January & February & march & April & May & June & July & August & September & October & November & December \\
\hline Almaty & $176 \cdot 10^{6}$ & $239 \cdot 10^{6}$ & $354 \cdot 10^{6}$ & $484 \cdot 10^{6}$ & $632 \cdot 10^{6}$ & $678 \cdot 10^{6}$ & $729 \cdot 10^{6}$ & $647 \cdot 10^{6}$ & $497 \cdot 10^{6}$ & $321 \cdot 10^{6}$ & $187 \cdot 10^{6}$ & $136 \cdot 10^{6}$ \\
\hline
\end{tabular}

Characteristic experiment: 4 (kg) oil wastes were mixed with 6 (l) of water and stirred thoroughly. Experiment was conducted with and without the use of solar panels. Results of these 
experiments are given in table 3 and 4.

Table 3 Results of measuring the temperature of oily waste without the use of solar panels

\begin{tabular}{|l|l|l|}
\hline Date:09. 08. $2014 \mathrm{y}$. & Ambient Temperature, ${ }^{0} \mathrm{C}$ & $\begin{array}{l}\text { The temperature of the mixture of } \\
\text { waste and water, }{ }^{0} \mathrm{C}\end{array}$ \\
\cline { 1 - 3 } Temperature measurement time & 29,4 & 26,1 \\
\hline $09: 00$ & 30,2 & 31,3 \\
\hline $10: 00$ & 33,7 & 46,7 \\
\hline $11: 00$ & 32,6 & 55,4 \\
\hline $12: 00$ & 33,8 & 68,9 \\
\hline $14: 00$ & 33,2 & 72,7 \\
\hline $15: 00$ & 35,8 & 85,2 \\
\hline $16: 00$ & 35,7 & 82,8 \\
\hline
\end{tabular}

Table 4 - Results of measuring the temperature of oily wastes with solar panels

\begin{tabular}{|l|l|l|}
\hline Date:08. 07. $2014 \mathrm{y}$. & Ambient Temperature, ${ }^{0} \mathrm{C}$ & $\begin{array}{l}\text { The temperature of the mixture } \\
\text { of waste and water, }{ }^{0} \mathrm{C}\end{array}$ \\
\cline { 1 - 1 } Temperature measurement time & 25,1 & 24,3 \\
\hline 09:00 & 26,8 & 31,3 \\
\hline $10: 00$ & 27,7 & 39,4 \\
\hline $11: 00$ & 29,8 & 49,9 \\
\hline $12: 00$ & 31,6 & 61,5 \\
\hline $13: 00$ & 33,9 & 72,1 \\
\hline $15: 00$ & 33,7 & 75,6 \\
\hline $16: 00$ & 33,2 & 75,3 \\
\hline
\end{tabular}

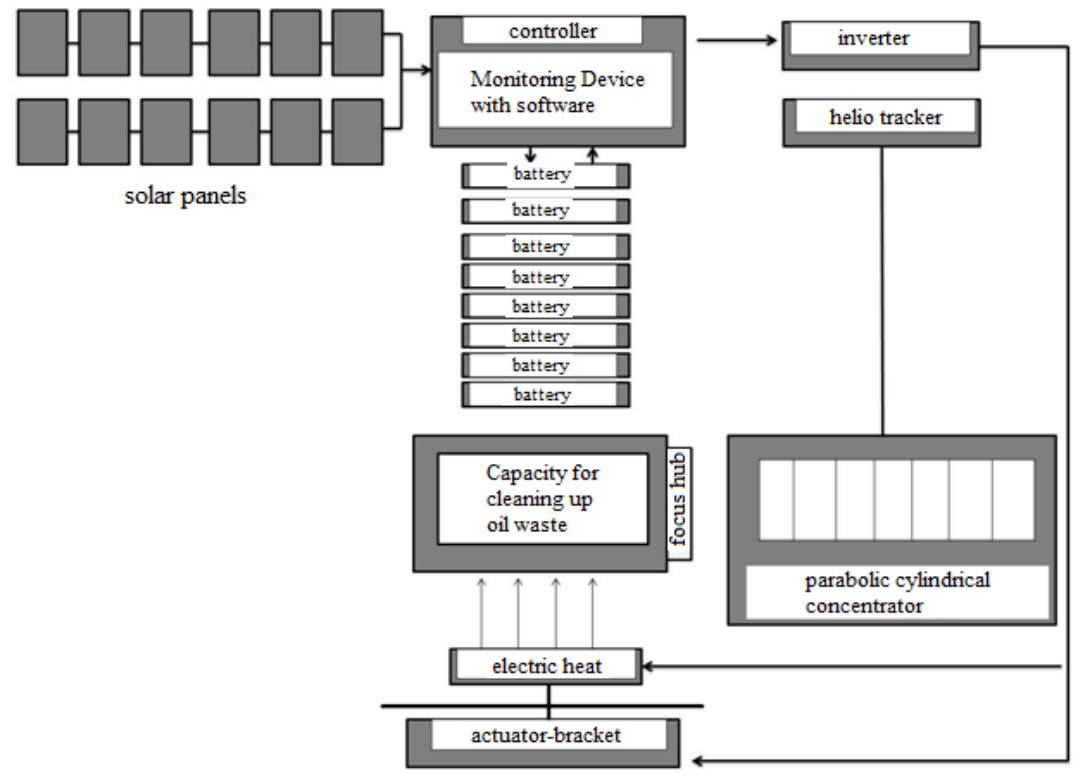

Fig.2. Schematic diagram of the Helio device equipped with concentrating elements

During experiment when heating waste oil temperature in the apparatus was $75-82{ }^{\circ} \mathrm{C}$ at the ambient temperature of $33-35{ }^{\circ} \mathrm{C}$, heating was carried out during daylight hours.Dynamics of change in the temperature of oily waste in Helio device equipped with concentrating elements, with and without the use of a solar panel is shown in Figure 4.

Researchof component composition of the petropolluted soil and oil sludge and their solid residues after preliminary processing with use of solar energy in the developed devicewas conducted for clarification of influence of thermal impact of solar energy on properties of hydrocarbons.Component composition of contaminated soils and solid residues after pretreatment using solar energy are shown in Table 5. 


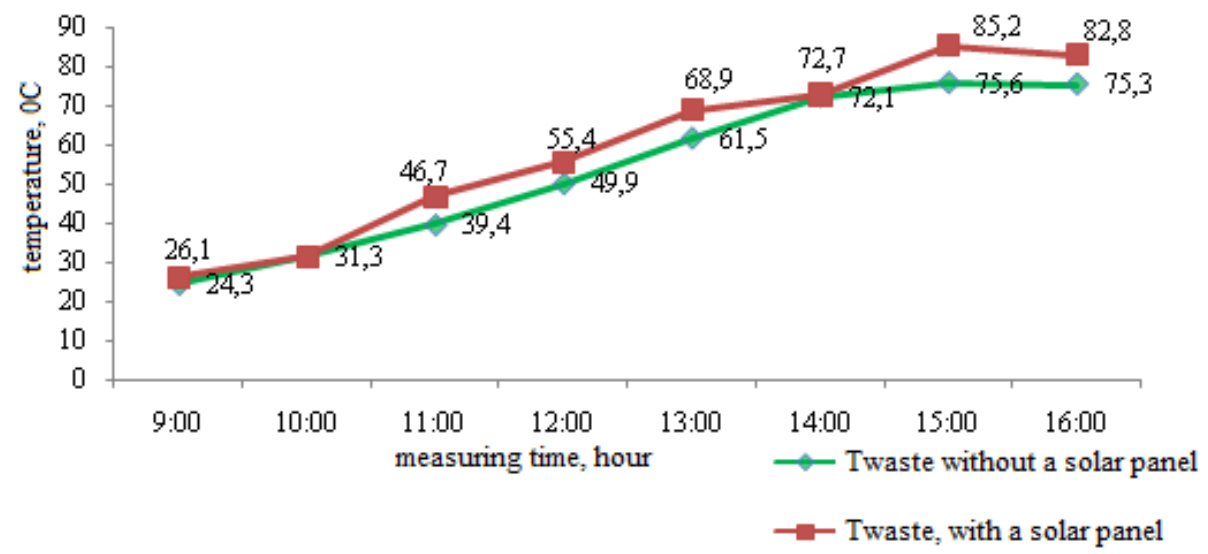

Figure 3. Dynamics of change in the temperature of oily waste using solar energy Table 5 Chemical composition of waste oil and solid residues before and after pre-treatment with the use of solar energy

\begin{tabular}{|l|c|c|}
\hline \multirow{2}{*}{ indicator } & \multicolumn{2}{|c|}{ value of the index } \\
\cline { 2 - 3 } & Before the treatment & after purification \\
\hline Density at $20^{\circ} \mathrm{C}, \mathrm{kg} / \mathrm{m} 3$ & 942 & 850,7 \\
\hline $\begin{array}{l}\text { Content of mechanical } \\
\text { impurities, \% by weight. }\end{array}$ & 76,8 & 6,79 \\
\hline Organic part of the masses. \% & 8,0 & 85,21 \\
\hline Water masses. \% & 15,2 & 8,0 \\
\hline
\end{tabular}

Thus, after pre-treatment of waste oil by using the solar energy in the ground solids content does not exceed 6,65-6,79\%. After purification, the hydrocarbons molecular masscloses in absolute valueto the bitumen.

\section{Conclusion}

Developed method of purifying oily waste solves an important environmental problem of disposal of oily waste, helps to restore and prevent degradation of natural systems, reducing pollution of soil and water.Recognizing new targets and defining newapproaches in the organization of complex processing of oily waste are urged to change the priorities of ongoing and planned activities for the purpose of protecting the environment.The mentioned method of cleaning oil waste -is the important component of the overall process of environmental safety.

\section{Reference}

[1] Chernyachovski V.J. Management of Environmental safety, M.: Publishing House «Alfa-Press», 2007, - p. 127;

[2] Kurochkin A.K. Tamm T. Oil sludge - resource materials for the production of light motor fuels and road bitumen, Oil and gaz sphere, №4, 2010 - p.72;

[3] Mkhitaryan N.M. Power of nontraditional and renewable sources. Experience and Prospects, NaukovaDumka, Kiev, 1999

[4] Omelyanenko K.V., Syroka A.Y. Program development of alternative energy in Kazakhstan / / Energy and Fuel Resources of Kazakhstan in 1993 with the number 4. 21 - 25;

[5] Kusainov S.G, Kusainov A.S., Toktamys E.I., Bedelbaeva G.E., A.O. Omarbekova. Concentrator solar energy dispersing properties, 2010;

[6] A.c. No. 62876. Device for cleaning of oil-contaminated soil, soil or sludge from petroleum products. Abdibattayeva M.M., etc. Published 01/15/2010: Newsletter No. 1;

[7] Nesterenkov A.G., Nesterenkov V.A., Shishkin A.A. Performance of solar module to the hub. / / Energy and Fuel Resources of Kazakhstan, 2010, № 4, p.30-32. 